\title{
A new photochromic system - potential limitations and perspectives
}

\author{
Heinz Dürr \\ FB 11, Organische Chemie Universität des Saarlandes \\ D-6600 Saarbrücken GERMANY
}

\begin{abstract}
:
A definition and a survey of property changes of photochromic systems is given. The known photochromic molecules are treated. A new class of photochromics is introduced, property changes are discussed and a short general overview of applications for classical and new systems is presented.
\end{abstract}

Chemistry, especially photochemistry is developing rapidly in new directions. Whereas in the past molecules and their properties have been in the center of interest this aspect is only the basis for further problems or questions. Functions of molecules are an additional requirement which have to be investigated. Functions open then a way to applications either in the field of material science or life sciences.

Photochromism is an exemplary field in this respect (ref. 1). This paper is treating these aspects in the context mentioned.

Photochromism can be defined in simple terms as a light induced (at last in one direction) conversion of a species $A$ to an isomer $B$, where $A$ and $B$ have different absorption spectra and energy content.

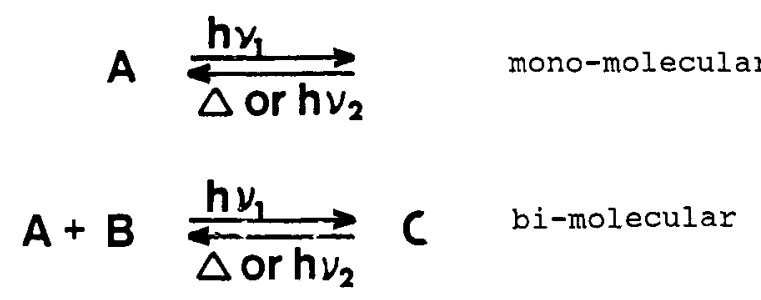

The higher energy content of $B$ in many cases is the driving force for an isomerization back to $\mathrm{A}$. The requirements for photochromism are

1) a light induced isomerization (in the visible spectrum) and 2) reversibility

This monomolecular definition has however to be extended to bimolecular reversible reactions.

A survey of property changes on the molecular and supramolecular level, possible in photochromic systems, is given in table 1.

Photochromic systems can involve very different structural or bond changes. The systems known are in many cases based on the following simple reactions or processes (ref. 2 ).

1) cis-trans-isomerization

2) pericyclic reaction

intramolecular electrocyclic reaction

intermolecular cycloaddition

3) tautomerism (H-transfer)

4) bond cleavage

5) electron transfer reactions

6) physical photochromic systems

An overview of the known photochromic classes is given first. 
TABLE 1. Reversible changes of properties in photochromic compounds and materials (adapted from Ichimura (ref. 1).

\begin{tabular}{|c|c|c|c|}
\hline \multirow[b]{2}{*}{ Properties } & \multicolumn{2}{|c|}{ Reversible change in } & \multirow[b]{2}{*}{ function } \\
\hline & $\begin{array}{l}\text { molecular } \\
\text { structure }\end{array}$ & $\begin{array}{l}\text { supramolecular } \\
\text { structures }\end{array}$ & \\
\hline \multirow[t]{2}{*}{ optical } & $\begin{array}{l}\text { absorption spectrum } \\
\text { emission spectrum } \\
\text { refractive index }\end{array}$ & $\begin{array}{l}\text { absorption spectrum } \\
\text { emission spectrum } \\
\text { optical rotatory } \\
\text { power } \\
\text { refractive index }\end{array}$ & $\begin{array}{l}\text { light scattering } \\
\text { birefringence }\end{array}$ \\
\hline & dielectric constant & dielectric constant & reflectivity \\
\hline chemical & $\begin{array}{l}\text { chelate formation } \\
\text { ion dissociation } \\
\text { enthalpy }\end{array}$ & $\begin{array}{l}\text { chelating formation } \\
\text { ion dissociation } \\
\text { enthalpy }\end{array}$ & $\begin{array}{l}\text { catalysis } \\
\text { enzyme activity } \\
\text { membrane } \\
\text { permeability }\end{array}$ \\
\hline electrical & & $\begin{array}{l}\text { conductivity } \\
\text { photoconductivity } \\
\text { capacitance }\end{array}$ & $\begin{array}{l}\text { membrane } \\
\text { potential }\end{array}$ \\
\hline $\begin{array}{l}\text { bulk or } \\
\text { supramol. }\end{array}$ & $\begin{array}{l}\text { phase transition } \\
\text { solubility }\end{array}$ & $\begin{array}{l}\text { phase transition } \\
\text { solubility } \\
\text { viscosity } \\
\text { wettability } \\
\text { density } \\
\text { elasticity }\end{array}$ & \\
\hline
\end{tabular}

Scheme 1 shows selected examples for each class of photochromic molecules (ref. 2-18).

\section{Scheme 1}

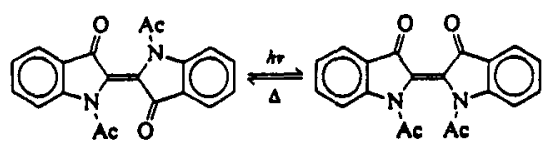<smiles>[R]c1ccc2c(c1)CCC1(N(C)c3ccc([R])cc3C1(C)C)C2(C)C</smiles><smiles>[C]1C[C@H]2C[C@H]1C2</smiles>

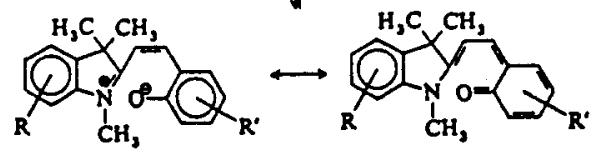

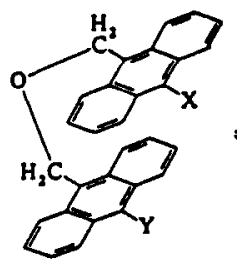

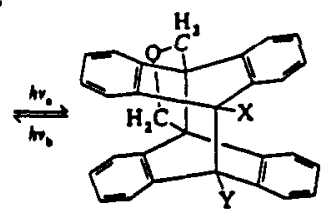

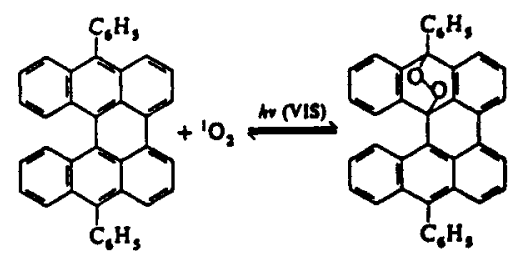

\section{A NEW PHOTOCHROMIC SYSTEM}

Pericyclic reactions are among the most important processes that allow to design and construct a photochromic system. From the processes in scheme 2 the cyclopentenyl-/pentadienyl-anion interconversion has been shown to be highly efficient in the synthesis of 5 membered ring heterocycles (ref. 19).

However no photochromic system based on the 1,5-electrocyclization of pentadienyl- to cyclopentyl anions (or its hetero- derivatives) has been reported in the recent past. We discovered in 1979 (ref. 20) new photochromic molecules based on this pericyclic reaction. 
Scheme 2

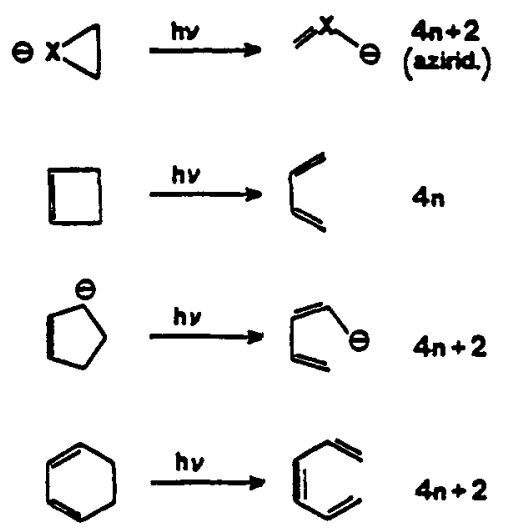

Scheme 3

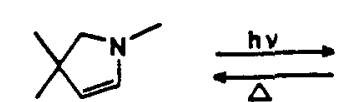

1<smiles>[R]C1=C([2H])C23C=CC=CN2C([R])=C13</smiles>

$\underline{3}$

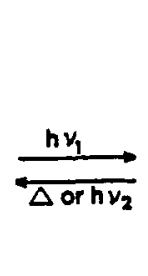

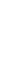
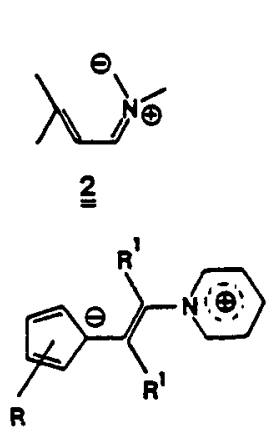

$\stackrel{4}{=}$
Scheme 4

category of $\begin{gathered}\text { dipolar } \\ \text { structure } \\ \text { cyclization }\end{gathered}$

The aza-cyclopentene 1 can undergo a photoinduced electrocyclic ring opening to the aza-pentadiene 2 . 1,5-electrocyclization will form the cyclic molecule $\underline{1}$ again. These structural elements are incorporated in the molecules 3 and 4 .

Related systems based on the mono-, bis- or tris-aza-cyclopentadiene interconversion were found slightly later (Scheme 4) (ref. 2, 2124).

\section{CHARACTERIZATION OF THE NEW SYSTEM/MOLECULAR PROPERTIES}

The photochromic spiro-dihydroindolizines $\underline{3}$ and its colored form the betaine 4 , as well as its analogs (Scheme 4 ), show characteristic spectral changes.

Irradiation of $\underline{3}(\lambda \max : 360-420 \mathrm{~nm}$ ) with visible light produces the colored betaine $\underline{4}$. The betaine $\underline{4}$ absorbs in an extended spectral region between 500-730 nm. This absorption range is important for applications in simple or more complex devices.

In addition mono- photochromic molecules based on the pyrrolin 1 aza-pentadiene $\underline{2}$ interconversion more sophisticated bis-photochromic molecules where prepared (ref. 25,26).

These compounds are also photochromic but show a more complex behavior (see 25,26$)$.

\section{Properties}

The thermal 1,5-electrocyclization of $\underline{4} \rightarrow->\underline{3}$ was studied and the thermodynamic parameters for this reaction were determined. $A$ structure reactivity relationship could be established and is based on both semiempirical calculations as well as $x$-ray structure determinations. 
The main result was that the regions $A, B$ and $C$ of the indolizines $\underline{3}$ (and its analogs) control

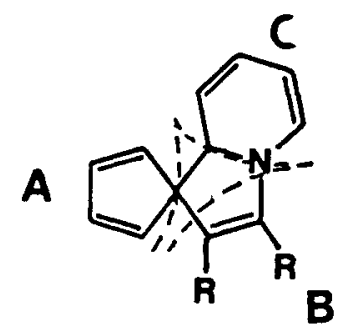

1) the rate of $1,5-e l e c t r o c y c l i z a t i o n ~ 4-->3$ (parameter:k or $t_{1 / 2}$ ), 2) $\lambda$ max of betaines $\underline{4}$ (and indolizines $\underline{3}$ ). This is essential for designing tailormade molecules with very special properties.

The 1,5-electrocyclization $\underline{4} \rightarrow-\rightarrow \underline{3}$ was shown to be both regio- (ref. 27) and stereo-selective (ref. 28,29).

\section{Photophysical studies}

A photophysical investigation of the photochromic indolizines 3 is given in the following section. Multiplicity studies show that the reaction $\underline{3}-\rightarrow \underline{4}$ proceeds on an excited singlet path. The stereochemistry of the electrocyclic ring opening $3 \rightarrow->4$ shows the validity of simple Woodward-Hoffmann arguments for this interconversion. Typical rate data for the photoinduced ring opening $\underline{3} \rightarrow->$ are collected in table 2 (ref. 30 ).

Table 2. Rate data for the photoreaction of dihydroindolizines $\underline{3}$ to betaines $\underline{4}$.

\begin{tabular}{|c|c|c|c|c|c|c|c|}
\hline 2 & $\begin{array}{c}T_{S} \\
{[\mathrm{~ns}]}\end{array}$ & $\begin{array}{l}D_{\mathrm{F}} \\
\cdot 10^{3}\end{array}$ & $\begin{array}{c}k_{F} \\
{\left[s^{-1}\right]}\end{array}$ & $g_{R}^{a)}$ & $\begin{array}{l}k_{i c} \\
{\left[s^{-1}\right]}\end{array}$ & gIC & $\begin{array}{c}\left.k_{R}^{a}\right) \\
{\left[s^{-1}\right]}\end{array}$ \\
\hline 1 & 1,94 & - & - & 0,43 & $2,20.10^{8}$ & 0,67 & $3,41 \cdot 10^{8}$ \\
\hline 2 & 0,68 & - & - & 0,35 & $5,12 \cdot 10^{8}$ & 0,65 & $9,61 \cdot 10^{8}$ \\
\hline 3 & 0,21 & 3,5 & $1,74 \cdot 10^{7}$ & 0,63 & $3,00 \cdot 10^{9}$ & 0,36 & $1,74 \cdot 10^{9}$ \\
\hline 4 & 0,42 & 2,2 & $5,24 \cdot 10^{6}$ & 0,58 & $1,38 \cdot 10^{9}$ & 0,41 & $9,76 \cdot 10^{8}$ \\
\hline 5 & 0,50 & - & - & 0,80 & $1,63 \cdot 10^{9}$ & 0,20 & $4,04 \cdot 10^{8}$ \\
\hline 6 & 0,15 & 1,0 & $3,12 \cdot 10^{6}$ & 0,70 & $4,67,10^{9}$ & 0,29 & $1,93 \cdot 10^{9}$ \\
\hline 7 & 0,43 & 2,3 & $5,40.10^{6}$ & 0,56 & $1,30.10^{9}$ & 0,43 & $1,00 \cdot 10^{9}$ \\
\hline
\end{tabular}
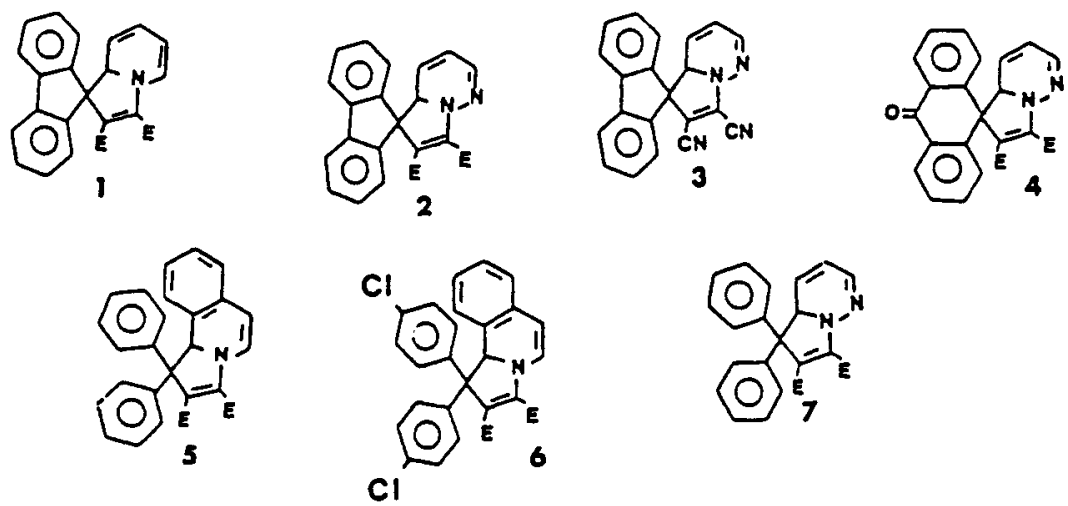


\section{APPLICATIONS}

Based on structural changes in photochromic molecules various property changes are to be envisaged. These can be optical, chemical, electrical or bulk changes (see table 1). A short survey of well established or potential applications beeing based on these variations or functions is given in table 3. Only functions based on optical and chemical properties have been selected.

Table 3. Selected examples of classical or new potential fields for application of photochromic systems

\begin{tabular}{lll}
\hline Molecule & $\begin{array}{l}\text { Property Change } \\
\text { optical: }\end{array}$ & Application \\
\hline DHI 3 & absorption & light filters \\
Spirooxazines & (color change) & light protection \\
Fulgides & & actinometers \\
Azobenzene & & dosimetry \\
Arom. Endoperoxides & & photoimaging
\end{tabular}

Azobenzene

DHI 3

Fulgides

spiroxazines absorption refractive index

chemical: enthalpy information storage

a) images

b) digital

solar energy

storage

Typical important classical applications are collected in table 3 . Recent developments in the field lie in supramolecular or environmental effects (ref. 31) in or with photochromic systems. Proper use of functions of photochromic systems in supramolecular assemblies, in special phases or environment allows to construct complex systems which may be used in an analogous or digital way in displays, non destructive read -write systems, non linear optics, optical holographic data storage and molecular electronics (ref. 1,2 ).

\section{REFERENCES}

1) a H.Dürr, H.Bouas-Laurent, Ed. Photochromism-Molecules and Systems, Elsevier Amsterdam, 1990.

b G.H.Brown, Photochromism, Wiley Interscience, New York 1971

2) H.Dürr, Angew.Chem., 101 (1989) 427; Int. Ed. Vol. 28, 4, 413.

3) a H.D.Scharf, J.Fleischhauer, H.Leismann, I.Ressler, W.Schlecker, Angew.Chem. 91 (1979) 696; Int.Ed. 18 (1979) 652 .

b E.Schumacher, Chimia 32 (1978) 193.

4) E.F.Ulman, J.E.Milks, J.Am.Chem.Soc. 84 (1962) 1315.

5) A.M.Trozzolo, W.Yager, G.Griffin, H.Kristinsson, I.Sarkar, J.Am.Chem.SoC. 89 (1967) 3357.

T.Do.Minh, A.M.Trozzolo, ibid 94 (1972) 4046.

6) R.J.Hart, H.G.Heller, J.Chem.Soc. Perkin Trans. 1 1972, 1321.

7) P.J.Darcy, R.J.Hart, H.G.Heller, J.Chem.Soc. Perkin Trans 1 $1978,571$.

8) V.Bockelheide, J.B.Philips, J.Am.Chem.Soc. 89 (1967) 1695.

9) V.Bockelheide, W.Pepperdine, J.Am.Chem.SoC. 92 (1970) 3684.

10) E.D.Bergmann, A.Weizmann, E.Fischer, J.Am.Chem.Soc. 72 (1950) 5009 .

11) E.Fischer, Y.Hirshberg, J.Chem.SOC. 1952, 4522 .

12) A.Castellan, J.M. Lacoste, H.Bouas-Laurent, J.Chem.Soc. Perkin Trans 2 1979, 411.

13) R.Schmidt, R.Drews, H.D.Brauer, J.Phys.Chem. 86 (1982) 4909.

14) A.Senier, F.G.Shepheard, J.Chem.Soc. 95 (1909) 1943; 101 (1912) 1950.

15) V. de Gaouck, R.J.W. Le Févre, J.Chem.Soc. 1939, 1457.

16) F.Feichtmayr, G.Scheibe, Z.Naturforsch. B 13 (1958) 51.

17) E.P.A.Zweegers, C.A.G.Varma, J.Phys.Chem. 83 (1979) 1821. 
18) G.Gliemeroth, K.M.Mader, Angew.Chem. 82 (1970) 421; Int.Ed. 9 (1970) 434 .

19) R.Huisgen, Angew.Chem. 92, (1980) 979; Int.Ed. 19 (1980) 947.

20) G.Hauck, H.Dürr, Angew.Chem. 91 (1979) 1010; Int.Ed. 18 (1979) 945 .

21) H.Dürr, A.Thome, U.Steiner, T.Ulrich, E.Rabe, C.Krüger, J. Chem.Soc. Chem. Commun. 1988, 338 .

22) V.Bach, Diplomarbeit, Universität Saarbrücken 1984. T.L.Gilchrist, C.W.Rees, J.Chem.Soc. C 1968, 779.

23) H.Dürr, C.Schommer, T.Münzmay, ibid. 98 (1986) 565 and 25 (1986) 572 .

24) C.Schommer, Thesis Universität Saarbrücken 1987. C.Dorweiler, T.Münzmay, P.Spang, M.Holderbaum, H.Dürr, E.Raabe, C.Krüger, Chem.Ber. 121 (1988) 843.

25) P.Spang, Thesis, Universität Saarbrücken 1985. H.Dürr, P.Spang, Angew.Chem. 96 (1984) 277 . Int.Ed. 23 (1984) 241.

26) H.Dürr, M.Holderbaum, E.Hadjoudis, J.Photochem., in print.

27) P.Spang, see 25.

28) H.Dürr, P.Scheidhauer, J.Besse, XI IUPAC Symposium, 1986, Abstr. 202.

29) J.Besse, Masters Thesis, Universität Saarbrücken 1990.

30) P.Scheidhauer, Thesis, Universität Saarbrücken 1987.

31) WSOCP (Workshop on Supramolecular Chem. and Photochem.), Saarbrücken 1989. 